\title{
A rare case of spondyloarthropathy: Iatrogenic hypoparathyroidism
}

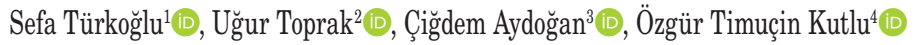 \\ ${ }^{1}$ Department of Radiology, Denizli State Hospital, Denizli, Turkey \\ ${ }^{2}$ Department of Radiology, Osmangazi University Medical Faculty, Eskişehir, Turkey \\ ${ }^{3}$ Department of Physical Medicine and Rehabilitation, Artvin State Hospital, Artvin, Turkey \\ ${ }^{4}$ Department of Internal Medicine, Süleyman Demirel University Medical Faculty, Isparta, Turkey
}

Received: March 28, 2018 Accepted: October 12, 2018 Published online: March 03, 2020

\begin{abstract}
Hypoparathyroidism is an endocrinopathy that can develop idiopathically, as well as due to reasons associated with genetics, autoimmunity, surgery and radiotherapy. It usually presents with neuromuscular signs and symptoms, including enthesopathy caused by calcification of the ligament and enthesis sites, soft tissue calcification, hypertension, cataract and extrapyramidal findings due to basal ganglia calcification. Hypoparathyroidism-associated spondyloarthropathy (SpA) is a rarely seen clinical entity. Hypoparathyroidism-associated SpA differs from other inflammatory SpAs in that the results for human leukocyte antigen B27 and inflammatory markers are negative and bone density is normal. The symptoms are relieved by calcium and vitamin D, rather than anti-inflammatory drugs. Due to this difference in treatment modalities, the diagnosis of this type of SpA is important. This article presents the case report of a 52-year-old female patient with iatrogenic hypoparathyroidism accompanied by asymptomatic hypocalcemia and SpA clinic.
\end{abstract}

Keywords: Calcification, hypocalcemia, hypoparathyroidism, spondyloarthropathy.

Hypoparathyroidism is an endocrinopathy characterized by inadequate parathyroid hormone (PTH) release and low serum calcium and high phosphorus levels. The etiology of hypoparathyroidism includes autoimmune, genetic and radiotherapy-related causes and past surgery. ${ }^{[1,2]}$ Hypoparathyroidism is common after thyroid surgery. In a case study with 233 patients, Pelizzo et al. ${ }^{[3]}$ reported the rates of transient and permanent hypoparathyroidism following thyroid surgery as $36.4 \%$ and $3.3 \%$, respectively.

In hypoparathyroidism cases, numbness, tetany, laryngospasm, carpopedal spasm and convulsions can be seen due to hypocalcemia. Some patients can also present without hypocalcemia symptoms but may experience lower back and neck pain of inflammatory character in thelongterm. ${ }^{[2,3]}$ In addition to enthesopathy due to the calcification of ligament and enthesis sites, widespread pain, postural disorders and limited vertebral movements, the presence of periarticular, paraspinal, vertebral and subcutaneous calcification and ligament calcification in radiological examination can lead to the misdiagnosis of inflammatory spondyloarthropathy $(\mathrm{SpA})$ and the administration of unnecessary treatments. ${ }^{[4]}$ In this article, we present a case of iatrogenic hypoparathyroidism manifesting without hypocalcemia symptoms but accompanied by SpA clinic.

\section{CASE REPORT}

A 52-year-old female patient was admitted to our physical medicine and rehabilitation clinic with the complaints of morning stiffness that lasted an hour and lower back and hip pain that was not relieved by rest for the past five years. She reported malaise and fatigue that continued all day and she also suffered from muscle cramps and numbness. The routine examination did not reveal oral/genital herpes, dry mouth/eye, diarrhea, constipation, abdominal pain, fever, night sweating, or weight loss. Her medical history included a subtotal thyroidectomy 25 years ago 
and cataract operation four years ago. It was discovered that the patient had been frequently using nonstreroidal anti-inflammatory drugs (NSAIDs) for her diagnosed SpA for years. A physical examination revealed limited range of motion in the cervical, thoracic, lumbar and hip joints. The patient's axial spine mobility was assessed by Bath Ankylosing Spondylitis Metrology Index-3. The result of modified Schober's test was $5 \mathrm{~cm}$, the occiput wall distance was $10 \mathrm{~cm}$, the lumbar lateral flexion was $5 \mathrm{~cm}$, the intermalleolar distance was $80 \mathrm{~cm}$ and the cervical rotation was $60^{\circ}$. The patient's axial spine mobility was moderately limited. ${ }^{[5]}$ Sacroiliac compression, Mennell's sign and Gaenslen's test were positive. There was tenderness on palpation of the bilateral plantar fascia.

The results of the laboratory test were as follows: serum calcium $6.7 \mathrm{mg} / \mathrm{dL}$ (8.8-10.6), phosphorus $5.8 \mathrm{mg} / \mathrm{dL}$ (2.5-4.5), PTH $10.8 \mathrm{pg} / \mathrm{mL}$ (15-65), 25-hydroxyvitamin D3 $10.35 \mathrm{ng} / \mathrm{mL} \quad(20-100)$, sedimentation $37 \mathrm{~mm} / \mathrm{h}$ and C-reactive protein $1 \mathrm{mg} / \mathrm{L}$ (0-3). The complete blood count, liver and kidney function, rheumatoid factor, anti-nuclear antigen and human leukocyte antigen B27 (HLA-B27) were within the normal ranges.

On sacroiliac magnetic resonance imaging (MRI), there were bilateral chronic sacroiliitis findings according to the criteria of the Assessment of SpondyloArthritis international Society. ${ }^{[5]}$ A foot MRI revealed talocalcaneal osteitis signs, plantar fasciitis and Achilles tendinitis, and the cranial MRI showed mineral deposits in the bilateral basal ganglia (Figure 1).

The patient was prescribed stretching and strengthening exercises and referred to the endocrine and metabolic diseases polyclinic, where she was started on calcium carbonate ( $2 \mathrm{~g} /$ day) and calcitriol (1 microgram/day) treatment. A written informed consent was obtained from the patient.
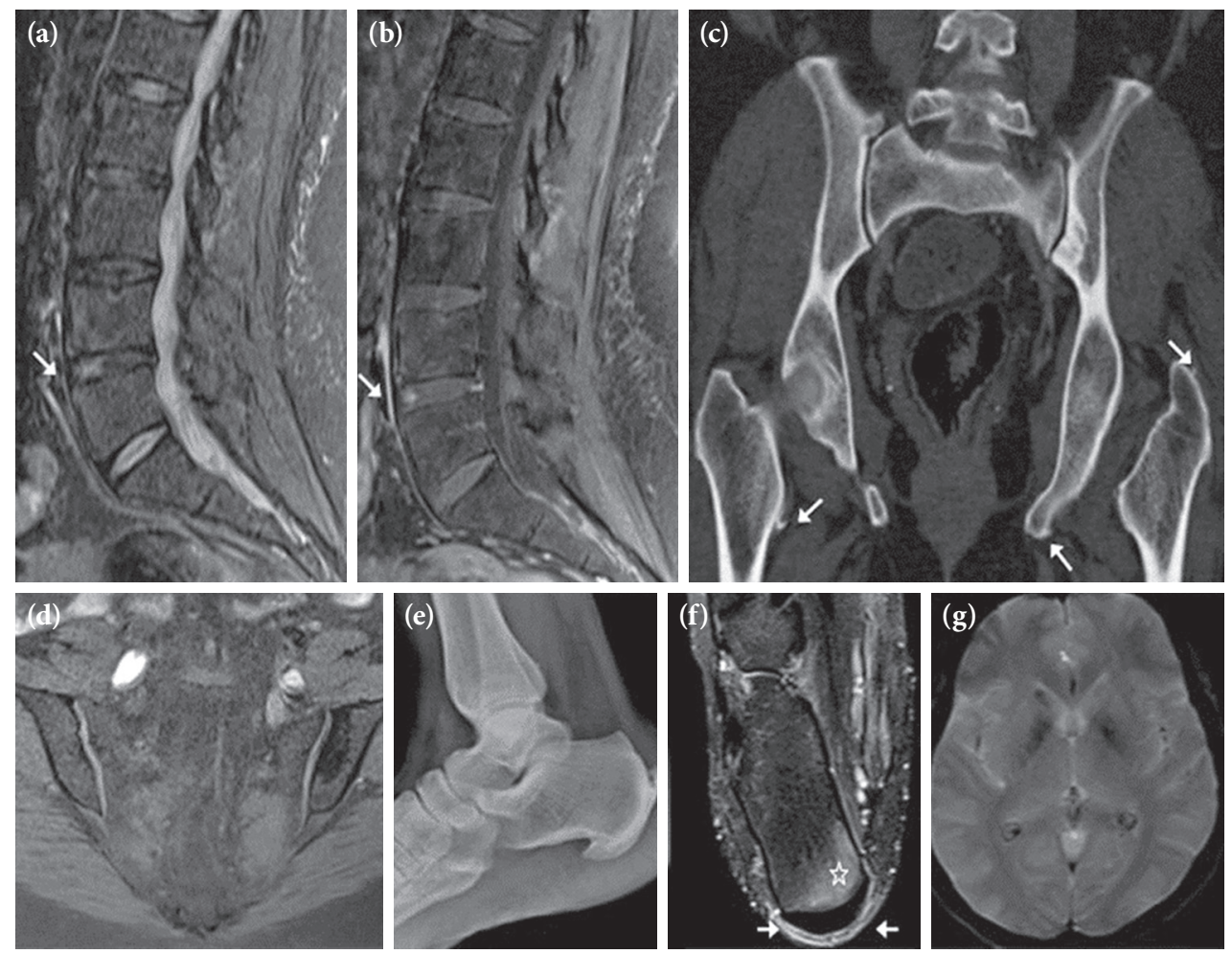

Figure 1. A 52-year-old female patient with spondyloarthropathy secondary to hypoparathyroidism. Short TI inversion-recovery (a) and contrast-enhanced fat-suppressed T1W (b) sagittal magnetic resonance imaging (MRI) reveal discitis at L4-5 and osteitis in anterior superior corner of L4 (arrows). Coronal pelvic computed tomography (c) shows enthesophytes (arrows) and a coronal T1W fat-suppressed MRI (d) reveals signs of chronic sacroiliitis in sacroiliac joints. In lateral roentgenogram (e), calcaneal enthesophytes are present, and in axillary fat-suppressed T2W MRI (f), bone marrow edema (star) and paratendonitis (arrows) are observed. Gradient-weighted axial brain MRI section (g) demonstrates signal loss in basal ganglia due to mineral deposits. 


\section{DISCUSSION}

Thyroidectomy is the most commonly performed endocrine surgery and the most frequent complications of thyroidectomy are hypocalcemia and recurrent laryngeal nerve injury ${ }^{[6]}$ Hypocalcemias that develop after thyroid surgery are divided into two groups of transient and permanent. ${ }^{[7]}$ Page and Strunski ${ }^{[8]}$ reported $35 \%$ transient hypocalcemia after total thyroidectomy, $3 \%$ persistent hypocalcemia at the postoperative sixth month and $1.4 \%$ permanent hypocalcemia at the postoperative second year.

Among the causes of transient hypocalcemia are the surgical technique, damage to parathyroid glands, edema caused by disturbed blood flow, ischemia, infarction, accompanying autoimmune diseases, malignancy and neck dissection. ${ }^{[9]}$ Transient hypocalcemia can be attributed to many different causes while surgical technique is held responsible for permanent hypocalcemia. ${ }^{[10]}$ Although the current case only underwent a partial thyroidectomy, there was sufficient parathyroid damage to result in the development of hypoparathyroidism.

Parathyroid hormone provides for the hydroxylation of vitamin 25-hydroxyvitamin D3 to 1,25-dihydroxyvitamin D3 in the kidney, absorption of calcium from the intestines and kidneys and excretion of phosphorus. In PTH deficiency, hypocalcemia and hyperphosphatemia may occur. ${ }^{[11]}$ In the absence of a timely diagnosis of hypoparathyroidism, soft tissue and excessive calcification of bone tissue may develop due to hyperphosphatemia. ${ }^{[12]}$ In the long term, patients may present with clinical and radiological findings of hypoparathyroidism without symptoms of hypocalcemia. Among these findings are intracranial calcifications, generalized atherosclerosis and increased bone density. Spondyloarthropathy signs, such as syndesmophytes, sacroiliitis and enthesopathy can also be seen, albeit rarely. ${ }^{[2]}$ For the current case, NSAIDs had been prescribed due to a diagnosis of SpA for years, and the possibility of hypocalcemia had not been investigated.

Spondyloarthropathies are a systemic disease group characterized by the inflammation of vertebrae, peripheral joints and structures around the joints. They are accompanied by inflammation at the enthesis sites and mostly HLA-B27 positivity. ${ }^{[1]}$ Due to the differences in the treatment of inflammatory $\mathrm{SpA}$ and hypoparathyroidism-associated SpA, a differential diagnosis followed by appropriate treatment is very important. ${ }^{[4]}$
When radiological findings are compared, in SpA, bone density is decreased, syndesmophytes are usually located in the lumbar and lower thoracic region, sacroiliitis is more common and is accompanied by erosion while new bone formation is not usually observed in the acetabulum. In hypoparathyroidismassociated SpA, syndesmophytes are located in the thoracic and upper lumbar, sacroiliitis is less common and it is not accompanied by erosion and new bone formation is observed in the acetabulum. ${ }^{[2]}$ In the current case, compatible with the latter diagnosis, there was no erosion of the sacroiliac joints but new bone formation was seen in the pelvis.

The first case of hypoparathyroidism mimicking SpA was reported in 1948 by Busher ${ }^{[13]}$ Numerous cases of idiopathic hypoparathyroidism have been described in the literature, while the number of postoperative cases is rare due to follow-up after surgery. Goswami et al. ${ }^{[14]}$ examined the clinical features of 40 patients with idiopathic hypoparathyroidism and found signs suggestive of SpA in 14 patients, sacroiliitis in 10 patients, and syndesmophytes in six patients. Inflammatory SpA and diffuse idiopathic skeletal hyperostosis should be considered in the differential diagnosis. ${ }^{[15]}$

The main purpose of the treatment of hypoparathyroidism-associated $\mathrm{SpA}$ is to normalize serum calcium and phosphorus levels. Treatment options include oral calcium, vitamin D and thiazide diuretics. Parathyroid hormone supplement can also be given to prevent soft tissue calcification. ${ }^{[2]}$

In conclusion, a diagnosis of hypoparathyroidismassociated SpA is usually delayed in patients being treated with an inflammatory SpA diagnosis. These treatments do not improve the condition of the patients and can even worsen their symptoms. Therefore, in cases of suspected SpA, levels of calcium, phosphorus and PTH should be investigated. Furthermore, the diagnosis should be reconsidered in patients who do not respond to anti-inflammatory and immunosuppressive treatment.

\section{Declaration of conflicting interests}

The authors declared no conflicts of interest with respect to the authorship and/or publication of this article.

\section{Funding}

The authors received no financial support for the research and/or authorship of this article.

\section{REFERENCES}

1. Jakkani RK, Sureka J, Mathew J. Spondyloarthropathy occurring in long-standing idiopathic hypoparathyroidism. Radiol Case Rep 2015;6:545. 
2. Illeez Memetoglu O, Unlu Ozkan F, Taraktas A, Aktas I, Nazikoglu C. Idiopathic hypoparathyroidism mimicking ankylosing spondylitis: A case report. Acta Reumatol Port 2016;41:82-5.

3. Pelizzo MR, Variolo M, Bernardi C, Izuzquiza M, Piotto A, Grassetto G, et al. Complications in thyroid resurgery: a single institutional experience on 233 patients from a whole series of 4,752 homogeneously treated patients. Endocrine 2014;47:100-6.

4. John DR, Suthar PP. Radiological features of long-standing hypoparathyroidism. Pol J Radiol 2016;81:42-5.

5. Sieper J, Rudwaleit M, Baraliakos X, Brandt J, Braun J, Burgos-Vargas R, et al. The Assessment of SpondyloArthritis international Society (ASAS) handbook: a guide to assess spondyloarthritis. Ann Rheum Dis 2009;68:ii1-44.

6. Sozen S, Emir S, Alıcı A, Aysu F, Ylldız F, Aziret M. Complication after thyroidectomy and the affecting factors related with surgeons. Ulusal Cerrahi Dergisi 2010;26:13-7.

7. Glinoer D, Andry G, Chantrain G, Samil N. Clinical aspects of early and late hypocalcaemia afterthyroid surgery. Eur J Surg Oncol 2000;26:571-7.

8. Page C, Strunski V. Parathyroid risk in total thyroidectomy for bilateral, benign, multinodular goitre: report of 351 surgical cases. J Laryngol Otol 2007;121:237-41.

9. Lefevre JH, Tresallet C, Leenhardt L, Jublanc C, Chigot JP, Menegaux F. Reoperative surgery for thyroid disease. Langenbecks Arch Surg 2007;392:685-91.

10. Algarni M, Alzahrani R, Dionigi G, Hadi AH, AlSubayea H. Parathyroid hormone and serum calcium levels measurements as predictors of postoperative hypocalcemia in total thyroidectomy. Gland Surg 2017;6:428-32.

11. Song L. Calcium and Bone Metabolism Indices. Adv Clin Chem 2017;82:1-46.

12. Özderya A, Sametoglu F, Dik İ, Niyazoglu M, Bedir B. Ankilozan Spondilit Bulgularını Taklit Eden Idiopatik Hipoparatroidili Bir Olgu. İstanbul Tip Dergisi 2007:4;49-5228-31.

13. Buscher B. Osteoartropathia parathreoiprive scleroticans. Rontgenpraxis 1948;17:252.

14. Goswami R, Ray D, Sharma R, Tomar N, Gupta R, Gupta N, et al. Presence of spondyloarthropathy and its clinical profile in patients with hypoparathyroidism. Clin Endocrinol 2008;68:258-63.

15. Sivrioglu K, Ozcakir S, Kamay O. Hypoparathyroidism: a rare cause of spondyloarthropathy. Scand J Rheumatol 2006;35:494-5. 